\title{
UM SHAKESPEARE POPULAR NO BRASIL DO SÉCULO XXI - ANOTAÇÕES EM TORNO DA APROPRIAÇÃO DE RICARDO III PELO GRUPO CloWNS DE SHAKESPEARE
}

Angélica Tomiello ${ }^{1}$

Alexandre Villibor Flory ${ }^{2}$

\begin{abstract}
Resumo: O modo como um texto estrangeiro pode ser ressignificado em diferentes culturas ganha contornos diversos a partir da perspectiva de trabalho de grupos teatrais que os encenem. É nesse sentido que representações de grupos de teatro brasileiro com viés popular ganham relevância ao refletir sobre o texto estrangeiro, levando em conta tanto a cultura-fonte do texto adaptado, quanto a cultura-alvo de recepção desses trabalhos. Nesse trabalho, muitas vezes, o viés popular questiona o caráter clássico do texto. Essa proposta de trabalho pode ser reconhecida como apropriação intercultural (PAVIS, 2015), uma perspectiva profícua de trabalho com atualizações necessárias para a compreensão de textos clássicos, principalmente quando provenientes de outras culturas. No caso deste artigo, o recorte, para exemplificação de como o trabalho com a literatura estrangeira no Brasil tem sido feito na contemporaneidade, recai sobre a encenação de Sua Incelença Ricardo III, pelo grupo potiguar Clowns de Shakespeare.
\end{abstract}

PALAVRAS-CHAVE: Literatura estrangeira. William Shakespeare. Adaptação. Teatro de grupo.

\section{A POPULAR SHAKESPEARE IN THE 21ST CENTURY IN BRAZIL -}

\section{NOTES AROUND RICHARD III'S APPROPRIATION BY CLOWNS DE SHAKESPEARE}

\begin{abstract}
The way a foreign text may gain new meanings in different cultures achieves diverse contours through the work perspective of the group which will search this text as reference. It is in these terms that the performances of Brazilian theatre groups with popular bias have earned relevance. Their work reflects on the foreign text the source-culture, from where the text is picked up as basis to their productions, as much as the target-culture that will compose the main reception context of these works. In this movement, we often see the status of the canon questioned through a popular bias. This work proposal may be recognized as intercultural appropriation (PAVIS, 2015), a useful proposal of work with necessary updates to achieve a better comprehension of classic texts, mainly those deriving from other cultures. To correspond to these statements, in this work, as an example of the contemporary use of foreign literature in Brazil, we analyze the theatrical performance of Sua Incelença, Ricardo III, made by the potiguar group Clowns de Shakespeare.
\end{abstract}

KEYwORDS: Foreign Literature. Shakespeare. Adaptation. Theatre groups.

1 UFPR, angelica.tomiello@gmail.com

2 UEM, alexandre_flory@yahoo.com.br 


\section{$244_{\text {caracaio } 8}^{\text {car }}$}

\section{Introdução}

O campo dos estudos teatrais sempre teve espaço limitado no âmbito dos estudos literários no Brasil, entendido por muito tempo apenas como texto dramático e, mesmo assim, com pouca atenção devido à sua natureza complexa, que exige uma dialética entre texto e cena, e pela suposta falta de importância do teatro para a arte brasileira - o que tem sido, paulatinamente, revisto.

No cenário contemporâneo essa situação vem se modificando, seja por conta da linha de pesquisa de literatura e outras artes, seja também pelas aberturas trazidas pelos estudos culturais, pois ambos olham para a literatura a partir de relações com outros campos artísticos e sociais. Com isso, torna-se viável estudar a relação entre literatura estrangeira e brasileira a partir da discussão sobre a encenação no Brasil de autores estrangeiros, o que é a base deste artigo.

Esse percurso é, sobretudo, pertinente e produtivo quando um grupo teatral brasileiro se propõe a fazer uma encenação de um texto estrangeiro. O diferencial é o que chamamos aqui de teatro de grupo. Os grupos teatrais "caracterizam-se como equipes de criação teatral que se organizam em cooperativas de produção, o que acaba determinando a autoria comum do projeto estético e a tendência à coletivização dos processos criativos (...)" (FERNANDES, 2009, p. 162) De acordo com a autora, há duas vertentes: uma que se aproximou das periferias, numa linguagem popular e politicamente articulada, à margem do mercado das artes, e outra linhagem formada por grupos que pesquisam novas linguagens cênicas. Nos dois casos, trata-se de grupos com pesquisa cênica continuada, formando repertórios que contribuem para a criação de uma história estética e social, para os quais a relação entre arte e sociedade é fundamental. Não são grupos formados especificamente para uma encenação, projeto esse mais voltado para o mercado e sem intenção de continuidade.

Esses grupos teatrais procuram formas de financiamento que sejam duradouras, e têm na formação de atores, diretores, iluminadores etc., bem como de público, um de seus eixos fundamentais. Lutam por editais de permanência por anos, e o caráter formador está em primeiro plano. Costa (2011, p. 55) faz um histórico do teatro de grupo no Brasil, identificando como momentos de referência fundamentais a trajetória do teatro de Arena, de São Paulo, e do CPC (Centro Popular de Cultura). Também Carvalho (2011), ao apresentar três ciclos de politização do teatro brasileiro ao longo do século XX (por volta dos anos 30, 60 e 90) mostra como esse teatro politizado está diretamente ligado com o teatro de grupo, especialmente nos anos 60 e nos anos 90, quando temos uma retomada deste modo de organização teatral.

Hoje, para citar apenas alguns grupos representativos, com no mínimo vinte anos de existência, temos o Ói nóis aqui traveiz, do Rio Grande do Sul (com 40 anos), o União e Olho Vivo, de São Paulo (46 anos) o Galpão, de Minas Gerais (37 anos), a Cia do Latão, de São Paulo (21 anos), o Clowns de Shakespeare, do Rio Grande do Norte (26 


\section{$24^{\text {crancacio \& }}$}

anos), entre outros. A longa lista deixa evidente que não se trata de algo específico, mas de um modelo estrutural para o teatro brasileiro.

O modo como esses grupos lidam com textos estrangeiros para serem encenados não será, como se pode imaginar, o da subserviência ao texto de partida, ou seja, o de uma suposta fidelidade ao clássico ou ao original. Importa a esses grupos de teatro, muito interessados no Brasil, em sua organização estética e social, buscar nos textos estrangeiros um diálogo produtivo com a cultura brasileira. Além disso, o caráter de pesquisa a que se entregam ao longo do tempo faz com que se coloque em questão, também, o próprio estatuto de clássico, tendo como pano de fundo um estudo de sua recepção ao longo do tempo.

Essa perspectiva vem de longa data: já no início dos anos 1960, o teatro de Arena de SP, naquela que foi chamada de sua fase de nacionalização dos clássicos, trazia para chão bem brasileiro peças como O melhor juiz, o Rei, de Lope de Vega, do século de ouro do barroco espanhol, invertendo simplesmente o núcleo central do desfecho, que conduziria para uma solução encaminhada pelo Rei, o melhor juiz, de acordo com o título; o diretor Boal faz o povo julgar a questão. Com isso, abandona o moralismo monárquico de Vega e despreza o moralismo burguês então vigente, para chegar a uma perspectiva popular e democrática. (MELLO, 2016) . $^{3}$

O grupo de teatro nordestino Clowns de Shakespeare, de 1993, faz algo análogo ao trazer o clássico inglês shakespeariano, articulado com uma proposta de teatro popular brasileiro, para um público também popular. Como o nome diz, encenam muitas peças de Shakespeare, valorizando a força e potência do autor, mas sem buscar algo como uma essência inalterável em seu teatro. O grupo realiza um questionamento de operação crítica em torno do cânone, que se torna importante pela reflexão sobre seu caráter supostamente eterno e atemporal, exigindo que se tome o clássico como uma construção histórica que deve ser atualizada para fazer sentido.

Nesse artigo apresentaremos, em linhas gerais, a estética do grupo Clowns de Shakespeare a partir da compreensão de como a literatura estrangeira - principalmente a obra shakespeariana - chega ao Brasil, pela forma teatral que marca esse grupo, para, em seguida, nos aprofundarmos na análise de alguns aspectos da encenação de Sua Incelença, Ricardo III, que esteve em cartaz pela primeira vez em 2010 e alcançou grande relevância no cenário nacional e latino-americano. Antes disso, contudo, faremos uma breve apresentação da recepção de Shakespeare no Brasil, para localizar a questão e observar como o texto shakespeariano foi trabalhado ao longo dos últimos dois séculos.

3 Conferir, em especial, a seção 3.5, intitulada O melhor juiz, o Rei: o caráter popular do Arena e seus impasses no interior do sistema capitalista de produção. 


\section{Criação \&}

\section{A presença de Shakespeare no Brasil na primeira metade do século XIX}

Assim como é difícil precisar com exatidão o início de qualquer movimento literário ou a primeira utilização de um determinado texto estrangeiro no Brasil, os primeiros passos da recepção da obra shakespeariana no Brasil não são facilmente mapeáveis pelos pesquisadores.

A literatura estrangeira, quando opera em contexto cultural diferente do original, toma rumos distintos, a partir da perspectiva daqueles que decidem o que será publicado, e com que abordagem, em termos de apropriação, tradução, interpretação, produção e difusão. Não raro a literatura estrangeira aparece remodelada por autores nacionais, em alguns casos referenciando a fonte, em outros apenas se apropriando de alguns elementos da trama, com ou sem remissão ao autor - caso muito comum na escrita de romances-folhetim publicados nos jornais do Rio de Janeiro a partir dos anos 30 do século XIX. Por isso, dentre outros motivos históricos de possibilidade e fomento da produção nacional, alguns dos primeiros registros que remetem aos textos de uma literatura inglesa no Brasil, envolvendo Shakespeare, aparecem como intertextualidades em produções de escritores brasileiros.

A produção bibliográfica feita no ano de 1959 por Gomes (1961) ajuda a elucidar a presença do dramaturgo inglês no Brasil. Ele o fez a partir de uma lista de documentos que indiquem quaisquer referências ao autor, sejam argumentos que o mencionem, sumários que o citem, como também traduções de suas obras em livros, trechos esparsos, sem esquecer a crítica estrangeira traduzida para o português, bem como as adaptações e paródias feitas a partir da apropriação de sua obra. De acordo com esse inventário, a maior presença de Shakespeare no Brasil a partir do século XIX se dá por representações teatrais de suas peças, que ganharam relevância, principalmente, com o ator João Caetano.

As encenações de Shakespeare no Brasil na primeira metade do século XIX trazem uma questão fundamental para sua recepção no país em torno das traduções utilizadas. As primeiras encenações de Shakespeare por João Caetano utilizavam, antes de serem traduzidas diretamente do inglês pelo próprio ator, versões "adocicadas" de Jean-François Ducis, retraduzidas por ele ou até por Gonçalves de Magalhães. Martins (2009) indica que o Otelo encenado em várias ocasiões por João Caetano foi traduzido por Gonçalves de Magalhães a partir da tradução de inspiração neoclássica de Ducis, haja visto ter sido publicada em 1842 com o subtítulo "uma tragédia de Ducis" - e não se ter usado uma tradução como a de Vigny, mais afeita ao espírito romântico (MARTINS, 2009, p. 28). Uma tradução original a partir do inglês de obra integral será publicada no Brasil apenas em 1933, feita por Tristão da Cunha (MARTINS, 2009, p. 29). As peças shakespearianas eram traduzidas para se adequar aos interesses do público que então se formava. Os verdadeiros dramalhões provenientes das traduções mencionadas eram famosos e implicavam em cortes no texto e numa representação grandiosa e excessivamente dramática, que marcava o sucesso das peças de João Caetano. 


\section{Criação \&}

Com isso, de modo correspondente às atualizações necessárias para produções shakespearianas na contemporaneidade, o século XIX o fez à sua maneira, levando em consideração o público a que se destina, seja para se adequar a determinados discursos dominantes, seja para se adequar ao gosto do público. Esse público, formado em grande parte por membros da corte portuguesa que chegou ao Brasil em 1808 e por brasileiros que procuram estar à altura dessa corte, se interessa por formas e temas europeus, ligados à monarquia e, apesar da independência em 1822, a Portugal - haja vista nossa independência ter sido feita por Dom Pedro I, herdeiro do trono português, e não por uma revolta contra este. Assim, a tradução a partir do francês funcionava até como uma maneira de valorizar a obra com a chancela de uma cultura elevada. As traduções de Ducis, de caráter neoclássico, seriam mais afeitas à prudência e à valorização da monarquia, contra os arroubos românticos de um Victor Hugo, marcado por invectivas contra a monarquia. Gonçalves de Magalhães, já mencionado, não apenas preferiu traduzir Shakespeare a partir de Ducis: seu primeiro drama, Antonio José ou o poeta e a inquisição, encenado em 1838 por João Caetano, procurava o meio-termo entre a aspiração trágica e o influxo romântico, de acordo com ele mesmo e, também, em sintonia com a crítica contemporânea (FARIA, 2011). Isso talvez diminua a estranheza e o certo incômodo com que Martins (2009, p. 29) anota o fato da tradução de Magalhães de Shakespeare buscar Ducis e não a tradução de Vigny: ao menos no teatro, seu romantismo (de Magalhães) era significativamente limitado.

Mas essa não era a única perspectiva com qual Shakespeare era apropriado no Brasil. A partir do cômico sempre presente na formação e desenvolvimento do teatro popular brasileiro, especialmente na comédia de costumes, que tinha enorme caráter crítico, questões sérias fundamentais para a vida social brasileira surgiram nos palcos brasileiros, incluindo nessas críticas até mesmo a idealização do estrangeiro. Ainda na primeira metade do século XIX, uma peça de Martins Pena como Os Dois ou o Inglês Maquinista, encenada em 1842, ridiculariza o culto ao estrangeiro.

Se buscarmos mais especificamente a apropriação de obras shakespearianas, encontramos, também de Martins Pena, a peça Os ciúmes de um pedestre ou o terrível capitão do mato, de 1846. Essa comédia de um ato se apropria, em partes, da peça $O$ Mercador de Veneza. Também Hamlet à força, de Leopoldo Brigido, produzida no ano de 1899, e O novo Othelo, de Joaquim Manoel de Macedo, de 1863, são exemplos de produções que se apropriam de textos shakespearianos para observar criticamente, através do viés cômico, algumas questões nacionais em seus contextos históricos específicos. Nesse sentido, a contraposição às traduções mencionadas até agora será realizada por apropriações cômicas, mostrando uma rica recepção da obra shakespeariana. 


\section{Criação \&}

\section{Tradução e apropriação de Shakespeare no século XX}

Tendo marcado esse início da recepção da tradução e da apropriação de Shakespeare na primeira metade do século XIX, o que também dá as bases metodológicas para o presente artigo, saltamos para o século XX. Com a modernização do teatro brasileiro ao longo da primeira metade do século $X X$, vemos uma maior liberdade para com os textos estrangeiros nos palcos. É nesse momento que representações que podemos chamar de apropriações começam a surgir efetivamente. Aqui, consideraremos apropriações como aquelas produções que, tendo a cultura-alvo como foco, produzem modelos interativos, dialéticos, significantes na atualidade, onde

[...] a transferência cultural não apresenta um escoamento automático, passivo, de uma cultura para outra. Ao contrário, é uma atividade comandada muito mais pela bola "inferior" da cultura-alvo e que consiste em ir procurar ativamente na cultura-fonte, como que por imantação, aquilo de que necessita para responder às suas necessidades concretas. (PAVIS, 2015, p. 3)

Nesse movimento não há nada definitivo quando se pensa num processo dialético. As trocas entre as culturas se mostram ativas, indicando alterações que ressaltam ou diminuem determinados traços da obra estrangeira tida como fonte para se tornar fonte de comunicação com a cultura produtora e consumidora, a cultura-alvo, enquanto questionadora de si própria a partir da observação do outro. Vê-se nesse processo quase uma proposição antropofágica, onde se devora o outro para observar-se. Após o modernismo, como essa remissão a Oswald de Andrade já indica, a perspectiva torna-se cada vez mais crítica, com intenção de discutir identidades nacionais, porém sem ufanismo ou qualquer idealização. O outro é entendido como ponto de partida para uma articulação produtiva com o texto original, levando-se em conta os contextos históricos locais. No caso do teatro, não há consenso sobre o momento no qual a modernização brasileira ocorre, ou um sistema teatral coeso, mas todos são unânimes em identificar o movimento de teatro amador nos anos 1940 (com grupos como Os comediantes, Grupo Universitário de Teatro - GUT, o Teatro Experimental do Negro - TEN, entre outros), e o surgimento de grupos empresariais como o Teatro Brasileiro de Comédia - TBC e o Teatro Maria Della Costa - TMDC, e de formação, como a Escola de Arte Dramática EAD (sintomaticamente, os três últimos de 1948, sendo o TPA o precursor do TMDC) são momentos decisivos do processo. Nesse momento, o teatro brasileiro começa, cada vez mais, a pensar diferentemente o modo como a literatura estrangeira chegava aos nossos palcos.

Os anos 1960 chegam e, com eles, como já visto, o Arena terá grande importância, mas muitos outros grupos também se inserem nesse contexto, como o Oficina, o CPC, o Grupo Opinião. Inseridos nesse escopo e carregando consigo toda uma 
carga histórica de formação do teatro nacional, grupos de teatro brasileiros que possuem viés popular, ainda hoje, promovem "adequações" da literatura estrangeira, de acordo com os princípios ideológicos e estéticos que organizam tais grupos, produzindo apropriações interculturais muito profícuas para o contexto de recepção.

Um exemplo é o Grupo Galpão, de Minas Gerais, criado em 1982 após uma oficina oferecida no Instituto Goethe, da qual surgem diversos aspectos estéticos que aparecem até hoje nos trabalhos do grupo. O seu trabalho é marcado pela polifonia de vozes nas representações, por técnicas circenses que vão da maquiagem ao uso de pernas de pau, o figurino, as técnicas de atuação (com músicas, danças, quebras na ilusão da representação) (GUERIOS, 2017, p. 47). Esses são alguns aspectos que tinham como intenção promover um teatro que propusesse reflexão aos espectadores. A pesquisa por uma linguagem própria procurava articular a inovação estética com a tradição teatral popular, das feiras, circos e praças ao ar livre. Deste modo, seu diálogo com textos considerados clássicos atemporais ganhava força justamente por questionar esse estatuto fechado, conseguindo resultados muito significativos. Para mencionar apenas alguns, o Galpão trabalhou com Molière, Shakespeare, Brecht, Pirandello, entre outros autores estrangeiros, a partir desta perspectiva. Como o grupo, desde sua criação, não possui um diretor fixo, contando com parcerias para as montagens, a estética tende a sofrer influências outras que tornam cada encenação algo único, e expõe o caráter múltiplo das encenações contemporâneas.

Uma de suas apropriações do texto shakespeariano ocorreu com a encenação de Romeu e Julieta, que, inclusive, foi encenado em praças londrinas bem como no Globe Theatre, em 2000 e 2012, após um sucesso enorme pelas praças do Brasil. A história dos apaixonados e o conflito das famílias do drama shakespeariano é trazido para terras mineiras. O grupo convidou, como dramaturgo responsável pelo texto, Cacá Brandão. Nas palavras de Guerios, o "trabalho de Brandão envolveu principalmente a concepção do estilo da linguagem da montagem, [...] inspirada na linguagem do sertão do romance Grande Sertão: Veredas (1956) de Guimarães Rosa (1908-1967)" (GUERIOS, 2017, p. $60)$. Eles trabalharam sobre a tradução de Onestaldo de Pennafort, de 1937. As pesquisas estéticas do grupo, articuladas com o registro próprio do diretor convidado, Gabriel Villela, compõem uma apropriação intercultural que traz a literatura estrangeira para o terreno brasileiro. Nesse processo, percebem-se elementos da cultura inglesa mesclados com os aspectos de construção teatral típicos do teatro brasileiro com viés popular. Entre outras coisas, a metáfora da lua, tanto por sua beleza quanto por sua inconstância, é importante tanto para o original shakespeariano quanto para a apropriação do Galpão, com a utilização de músicas como Lua Branca, entre muitas outras, que contribuem para uma relação muito proveitosa entre as duas culturas em cena.

Carregando as características próprias do teatro popular brasileiro, envolvendo o cômico e a crítica, o refletir sobre o território em que se inserem pela subversão do clown, com máscaras, figurinos muito bem trabalhados e uma construção pensada a partir de reflexões inclusive teóricas, o trabalho com a literatura estrangeira se mostra múltiplo e 


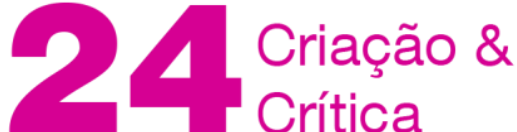

não estanque. Ao buscarem tais fontes literárias, ainda mais clássicos como Shakespeare, grupos como o Galpão e o grupo potiguar Clowns de Shakespeare ressignificam e atualizam esses clássicos, trazendo-os para uma recepção popular que, muitas vezes, estava também dada nas condições de produção dos originais, que não nasceram clássicos atemporais.

Esse olhar popular empresta força ao promover uma dialética positiva entre a cultura do país de chegada e do país de origem. Dois exemplos dessa relação se mostram quando, na capa de um livro produzido na Inglaterra, pela Cambridge University Press, vê-se uma foto da encenação de Romeu e Julieta do Galpão, ainda mais em um livro intitulado Shakespeare and the force of modern performance (WORTHEN, 2003) ${ }^{4}$. 0 crítico de teatro Charles Spencer revela o caráter positivo de uma produção como a do Galpão quando indica: "Eu garanto que você nunca terá visto um Romeu e Julieta como este. Romeu e Julieta do Galpão é um encanto louco e maníaco, prova persuasiva de que o Brasil é realmente de onde os loucos vêm. [...] abençoado com verdadeiro encanto" (GUERIOS, 2017, p. 118)5. No caso, a loucura é positiva, pois busca atualizar elementos que se perderam ao longo do tempo, e que o autor valoriza na apropriação brasileira.

Há que se notar, ainda, alguns aspectos da encenação que são fundamentais para o artigo, tendo em vista que a apropriação aqui em tela não se limita ao texto. No caso dos grupos supracitados, percebe-se uma preocupação muito grande em relação à oralidade, aliada a um significativo trabalho musical por canções que se articulam muito bem nos seus contextos culturais. Sabemos que o uso do pentâmetro iâmbico por Shakespeare não se deveu a algum projeto pomposo de elevação estética, de distinção nobiliárquica, mas entre outras coisas por se aproximar do ritmo da fala cotidiana, o que nos remete diretamente a uma preocupação com a oralidade - o que ajudava tanto os atores como o público. Quando um grupo como o Galpão e os Clowns de Shakespeare trazem essa dimensão para o seu trabalho, eles de alguma forma se aproximam da obra. No caso da aproximação com Guimarães Rosa, o resultado é ainda mais impactante, pois Rosa consegue aproximar oralidade de erudição, de tal forma que os pensamentos mais profundos cabem na dicção popular, e de certa forma isso também é importante para Shakespeare. É possível tomar conhecimento desse trabalho, e de outros que se apropriam de Shakespeare, pelo site MIT Global Shakespeares, que conta com gravações completas de diversas encenações realizadas no mundo inteiro, com letreiros em inglês. Nessas gravações é possível reconhecer como a retomada da literatura shakespeariana ganha novos significados extremamente relevantes para cada um dos contextos em que se inserem, inclusive no Brasil. Feita essa rápida apresentação a

4 Tradução nossa: Shakespeare e a força da performance moderna.

5 A partir da tradução da autora da dissertação. No original: "I guarantee that you will have never seen a Romeo and Juliet like this. Galpão's Romeo and Juliet is a mad and maniac delight, persuasive proof that Brazil really is where the nuts come from. [...] blessed with real charm." (GUERIOS, 2017, p. 118) 
respeito da encenação de Romeu e Julieta, do Galpão, é hora de nos voltarmos para os Clowns de Shakespeare. Não sem antes, todavia, lembrar que a remissão ao grupo mineiro não é aleatória: o grupo potiguar tem no Galpão uma referência fundamental e direta, o que também motivou essa visita preliminar.

\section{Clowns de Shakespeare: uma estética cômico-questionadora}

Fora do eixo Rio-São Paulo, onde se situa a maioria dos grupos de teatro, o grupo potiguar Clowns de Shakespeare, como visto, é um dos grupos que incorpora a literatura estrangeira em suas produções teatrais desde sua fundação - aliás, desde a escolha de seu nome. Como se propuseram a ser os "clowns", ou os bobos, de Shakespeare, desde o primeiro momento o grupo evidenciou uma posição lateral, visando não o núcleo dramático dos conflitos, mas uma perspectiva cômica que está presente nas peças. Assim como os bobos das peças shakespearianas, o grupo consegue assim uma maior liberdade para a sua atuação.

Outro aspecto que se revela já no nome do grupo é o conceito estético do clown. Não se trata de um trabalho com os palhaços para simplesmente comicizar, sem maiores pretensões, mas de utilizar a lógica subvertida do cômico como um instrumento de crítica e reflexão. Esse processo político se dá através da apropriação de textos da cultura estrangeira - em sua grande maioria, os textos shakespearianos - que fazem refletir sobre a sociedade em que se inserem. O cômico também é fruto de todo um percurso de formação do teatro brasileiro que, desde o século XIX, utilizou em suas produções o riso como uma forma de reflexão. Nas palavras de Arêas, apoiando-se em Northrop Frye: "[...] a comédia e a tragédia fazem parte do mesmo ritual que pretende dar conta do nascimento, morte e ressurreição do homem. Mas a tragédia nos ensina a inevitabilidade da morte, enquanto a comédia, a inevitabilidade da ressurreição. Segundo esse ponto de vista, a tragédia seria uma comédia incompleta" (ARÊAS, 1990, p.22). Com isso quer indicar que, se a tragédia discute conceitos definitivos, acabados, universais, a comédia lê esses conceitos como temporais, contextuais, efêmeros, e que todo fim é um recomeço; insinua que uma crise existencial pode se diluir com o passar do tempo, que um sofrimento amoroso pode ser em pouco tempo revertido em novo amor. De certa forma, a comédia acaba por perspectivar a tragédia - ou, no caso, o drama dito sério - mostrando que tudo é conjuntural e histórico, e não deve impedir a vida de seguir em frente. Em suma, a comédia pode ser tão ou mais profunda e filosófica que a tragédia ou o drama. Essa perspectiva anima a apropriação shakespeariana dos Clowns de Shakespeare.

A liberdade aqui explicitada não se faz de forma displicente nas representações, assim como nenhum outro aspecto do grupo em seu trabalho com o texto estrangeiro se apresenta casual. Em sua organização, desde o nome, o grupo toma o "[...] lirismo dos clowns de Shakespeare [...]" (BANDEIRA, 1986, p. 75), em sentido análogo ao proposto pelo autor Manuel Bandeira, o da liberdade de produção frente às amarras de concepções museológicas de trabalho artístico. 


\section{Criação \&}

A hybrid performance aesthetics - influenced by Oswald de Andrade's "Cannibalist Manifesto" (1928) and by Silviano Santiago's notion on hybridity or "space-in-between" (1970) - marks the Clowns' street performances. Andrade is a Brazilian modernist writer who anticipated theoretical perspectives on adaptation and appropriation later embraced by poststructuralist and postcolonial critics when, in his 1928 manifesto, he conferred legitimacy to "creative cannibalism" (a term he coined), grounded upon the productive borrowing of foreign cultural capital while affirming indigenous literary or cultural sources. Santiago is one of the first scholars to deconstruct binary oppositions, such as "center" and "periphery" and "original" and "copy". (CAMATI; LEÃO, 2016, p. 94)

Nesse sentido, uma das características estéticas do grupo já se revela: a perspectiva de trabalho sobre o texto estrangeiro não será feita como retomada de um clássico autossuficiente por seu estatuto de clássico, mas ocorrerá por meio de um trabalho com o texto que busque ressignificá-lo numa nova cultura, não por ser um texto canônico, mas pelas contribuições que ainda pode trazer para o novo contexto de recepção - o Brasil do século XXI, trazendo aspectos próprios desse mesmo contexto.

O trabalho profícuo com um texto de literatura estrangeira só se torna possível a partir de um sólido conhecimento da obra e de seu contexto de produção inicial. É por isso que, afinado com o que vimos sobre teatro de grupo, os Clowns são um grupo em constante renovação e com pesquisa continuada diante dos desafios de montagens realizadas e a realizar. O estudo de técnicas de atuação, sobre a presença do ator no palco, sobre a musicalidade, de trabalhos a respeito da obra tomada como fonte faz parte também do processo colaborativo de produção que visa horizontalizar as relações entre os participantes.

$\mathrm{Na}$ configuração do grupo não se vê um integrante determinando o comportamento dos demais; o diálogo é aberto e as funções assumidas durante a produção se alternam, resultando em um processo colaborativo. Para a encenação de Sua Incelença, Ricardo III, os Clowns trazem um diretor convidado, que traz uma proposta de trabalho específica para o grupo, observada, principalmente, nos exageros barrocos dos figurinos - um traço típico da estética já consagrada do diretor Gabriel Villela.

6 Em tradução livre do texto-fonte: Uma estética híbrida de performance - influenciada pelo "Manifesto Antropofágico" de Oswald de Andrade (1928) e pela noção de hibridização ou "entrelugar" de Silviano Santiago (1970) - marca as encenações de rua dos Clowns. Andrade é um escritor brasileiro modernista que antecipou perspectivas teóricas de adaptação e apropriação, mais tarde abarcadas pelas teorias críticas pós-estruturalistas e pós-coloniais, quando em seu manifesto de 1928, ele conferiu legitimidade ao "canibalismo criativo" (termo cunhado por ele), baseado no empréstimo produtivo do capital cultural estrangeiro ao mesmo tempo em que afirma fontes literárias e culturais indígenas. Santiago é um dos primeiros estudiosos a desconstruir oposições binárias como "centro" e "periferia" e "original" e "cópia" (CAMATI; LEÃO, 2016, p. 94). 


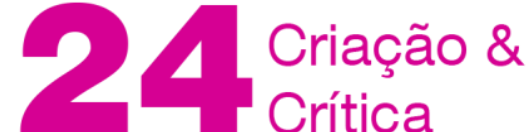

O grupo potiguar também se mobiliza para que a cultura popular nordestina ganhe espaço na encenação. Embora não busque uma representação mimética da realidade, o grupo se mantém vinculado à sua territorialidade, de onde retira elementos diversos de linguagem, de memória, de história local, mantendo uma certa autonomia de produção. Além dessa autonomia, é válido indicar como o grupo recebe influência do teatro épico-dialético proposto por Brecht (1978), já que utiliza diversos elementos épicos em suas encenações.

A grande maioria dos espetáculos do grupo ocorre em espaços de rua, seja em frente ao Barracão Clowns (Espaço Cultural Casa da Ribeira), em Natal, onde mantém sua sede, seja nos locais para onde o grupo leva suas encenações em festivais de teatro no Brasil e no exterior.

\section{Sua Incelença, Ricardo III entra em cena}

Fernando Yamamoto, o diretor fixo do grupo Clowns de Shakespeare, diz que, a partir da versão de Ricardo III traduzida por Anna Amélia Carneiro de Mendonça, o roteiro da encenação de Sua Incelença, Ricardo III foi construído pelo processo colaborativo que marca o grupo, inserindo contribuições à tradução que colocam o texto em uma nova localização temporal e cultural. De maneira análoga, o Galpão trabalhara com a tradução de Romeu e Julieta feita por Onestaldo de Pennafort, de 1937, numa apropriação do texto estrangeiro que tinha um dramaturgo (Brandão) estruturando o texto - como visto faz pouco neste artigo. Esse movimento - apesar de destacarmos aqui somente dois exemplos em dois grupos de viés popular brasileiros - parece integrar uma poética distintiva do trabalho com a tradução de textos teatrais estrangeiros no Brasil. Os cortes, a musicalização, os elementos cênicos típicos da cultura-alvo se transformam em instâncias narrativas dialéticas nessas produções contemporâneas.

Sabe-se que o teatro shakespeariano era muito marcado pela prosódia em cena, visto que havia cenografia mínima, conseguindo seu efeito pela imaginação criada por meio das falas. Noutras palavras, embora o texto seja de comprovada qualidade estética, isso não ocorria em detrimento da sua subida aos palcos - não era um teatro feito somente para ser lido, mas era um teatro fortemente marcado pelo texto, e daí chegamos à importância do texto em cena, que tem especificidades como uma tendência para a valorização da oralidade, de uma, por assim dizer, dramaturgia da voz. Essa dimensão, que depende obviamente do registro textual, mas, de modo algum, se limita a ele, é muito difícil de ser traduzida, ou adaptada, pois ela está fortemente ancorada no contexto contingente, efêmero, histórico de uma determinada cultura e lugar. Essa tradução como apropriação é decisiva para uma atualização que não idealize o contexto elisabetano de origem, e consiga falar francamente com diversos públicos brasileiros. Isso se torna central no trabalho com o texto realizado pelo grupo potiguar, no qual é possível perceber que o aspecto linguístico da apropriação foi, também, muito bem trabalhado. Entre outras coisas, eles se preocupam em trazer para a cena o sotaque e a dicção nordestinos - os 
acentos nasalizados típicos da região, a supressão de consoantes finais etc. -, usam uma concordância verbo-nominal coloquial, abusam de expressões locais, entre outras coisas. As variantes utilizadas não são as cultas, mas as usadas no dia a dia.

Um exemplo das coloquialidades presentes no texto ocorre numa das falas da rainha Elizabeth: "De tantas grosseria que suporto / Preferiria ser uma criada / A ser rainha nessas condição!" (YAMAMOTO, 2010, p. 5, grifo nosso). Essa fala, quando ganha vida na voz da atriz durante a encenação, usa ainda o sotaque local, a partir do alongamento das sílabas na pronúncia e da nasalização das vogais. Outra sentença que evidencia a sem-cerimônia das expressões utilizadas, longe da altura idealizada dos monarcas, se caracteriza pelo uso do palavrão, e vem novamente de Elizabeth, ao provocar Ricardo: "Ricardo, não confunda cu com bunda!" (YAMAMOTO, 2010, p. 5). Esse registro rebaixado ressalta, mais uma vez, o caráter popular do texto, já que se posiciona à altura da compreensão de diversos públicos, e não somente de um intelectualizado. Tanto se aproxima da proposta popular do período elisabetano, quanto da proposta do grupo em sua apropriação da literatura estrangeira.

Cumprindo a proposta estética do grupo em sua liberdade de produção, em nenhum momento a construção textual da apropriação busca fidelidade ao cânone. Muitos versos, se não cenas inteiras, foram suprimidas para dar espaço a expressões, inclusive repentes - cordéis musicalizados nos jogos feitos "de repente" - que traduzem para a cultura local, criando uma situação muito mais significativa para o novo contexto. Esses cortes deram espaço, inclusive, para uma perspectiva que remete ao teatro épico, com narrações explicativas que localizam os espectadores na proposta de encenação.

A produção do grupo tem influência da Commedia dell'Arte, somado ao aspecto circense do grupo Piolim com as 'deformações cômicas' e o teatro de rua, além de ser um reflexo ou produto do desenvolvimento teatral brasileiro que sempre contou com o cômico nas mais diversas formas encenadas. É interessante notar como o grupo retoma o caráter popular shakespeariano aliando essa popularização com elementos circenses e cômicos que tornam uma peça histórica, como Ricardo III, algo risível em suas apropriações ao território brasileiro onde é encenado inicialmente, com pantomimas e elementos cênicos próprios do contexto cultural do Nordeste. Importa notar que a apropriação de uma peça histórica a partir de uma matriz de comédia rebaixada (próxima da farsa, como o circo) faz com que o entrecho trágico saia perspectivado, distanciado, mostrando as nossas contradições. (AUTOR, 2018, p. 121)

A estética do diretor convidado Gabriel Villela se faz presente durante toda a encenação, principalmente pela caracterização e pelo figurino, como destacam Camati e Leão (2013) quando evidenciam como esse aspecto enriqueceu a obra 


\section{$244^{\text {cracasa \& \& }}$}

[...] pela estética barroca de Villela que prima pelo excesso, contraste de cores e inúmeras tendências costuradas para a criação dos figurinos, adereços e cenários, estabelecendo um diálogo profícuo entre a cultura popular, a tradição do circo e o teatro. É importante ressaltar que Villela inicia a concepção de seus espetáculos pelo figurino. Suas influências vêm de casa e da infância: a mãe era bordadeira e a tia modista. As referências, tanto para a direção geral do espetáculo, quanto para os figurinos e cenários, sempre passam pelas festas populares do interior de Minas Gerais. E, como indica o encenador, o figurino cria uma espécie de segunda "pele" para o ator e veste a alma da personagem, chegando aos olhos da plateia antes das palavras. (CAMATI; LEÃO, 2013, p. 220)

Com as sedas e metais que remetem ao contexto elisabetano inglês em contraste com o couro e as chitas próprios do contexto de produção donde se apropria a obra, o espetáculo ganha vida e ressignifica, inclusive, objetos comuns do dia a dia brasileiro em suas referências à peça shakespeariana Ricardo III. Compondo o cenário, nessa dialética intercultural, observa-se um palco circular, limitado por lanternas envoltas de palha e lampiões, que se apresenta a céu aberto, similar ao que se fazia no contexto elisabetano. Nessa escolha de espaço, o que salta aos olhos no primeiro momento é a presença de carroças que funcionam tanto como objeto referencial quanto como uma possibilidade de perspectivação da encenação em diferentes níveis para a atuação, ao indicarem mudanças de cenários quando trazidas para frente ou recuadas, por exemplo. Apesar desses elementos, muito pouco se observa de adornos indicativos em termos de construção cênica. Esses poucos são muito bem escolhidos e se relacionam ao contexto de produção elisabetano, que também não adornava em excesso os palcos das representações.

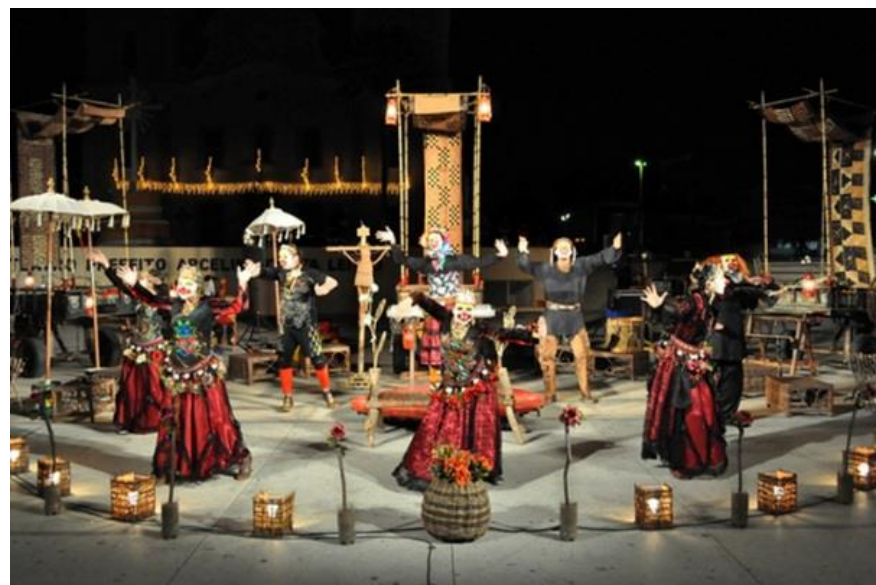

Figura 1 - Palco delimitado pelas lamparinas e perspectivado pelas carroças ${ }^{7}$

7 Clowns de Shakespeare misturam guerra inglesa e sertão nordestino em Sua Incelença, Ricardo III. Disponível em: <http://www.miguelarcanjoprado.com/2012/07/21/clowns-de-shakespearemisturam-guerra-inglesa-e-sertao-nordestino-em-sua-incelenca-ricardo-iii/>. Acesso em: 27 abr. 2019. 


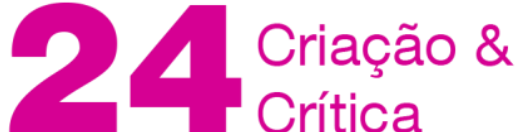

É importante notar que, nesse palco, que une os elementos da cultura popular nordestina a uma narrativa produzida no século $\mathrm{XVI}$, o figurino não se mantém igual do início ao fim. Dois parecem ser os motivos: devido à estética do grupo, que bebe do travestimento de mulheres em homens e do mascaramento típico da Commedia dell'Arte, e devido ao número reduzido de atores para um grande número de personagens presentes na peça. 8 atores teriam que dar vida à 54 personagens. Porém, como vários cortes foram feitos, nem todos os personagens do texto original foram mantidos "somente" 28 permanecem. A alternativa, que deriva também da estética do grupo, foi a troca dos figurinos durante a encenação, ou a alteração de vozes e modos de encenar. Um exemplo que podemos destacar ocorre com o ator César Ferrario, que tanto se apresenta como Clarence quanto como duquesa de York e, também, como o assassino contratado por Ricardo III, e que se assemelha aos jagunços nordestinos, Tyrrel Jararaca.

Com esse último personagem, observa-se mais um dos encontros entre culturafonte e cultura-alvo na apropriação do texto estrangeiro. $O$ assassino contratado por Ricardo III durante a peça shakespeariana é conhecido como Sir James Tyrrel (SHAKESPEARE, 2016, p. 1060). Já na representação do grupo potiguar, encontramos a referência a um cangaceiro famoso do grupo de Lampião, o Cabeleira, que também era conhecido como Jararaca por matar crianças apunhalando-as com sua espada após jogálas para o alto. Tyrrel Jararaca une as duas culturas em seu nome, suas atitudes, seu figurino, e dá lugar à mãe de Ricardo III em diferentes momentos, indicando bem o travestimento presente com um ator interpretando uma mulher (que se parece muito, inclusive, com Freddie Mercury).

Nessa última referência há ainda uma alusão política ao contexto cultural nordestino. $O$ assassino profissional do texto shakespeariano, no contexto inglês, cumpre determinadas tarefas para contribuir com a ambição e luta de Ricardo, em busca do trono. Esse aspecto se assemelha, em termos de significação contextual, às atitudes dos cangaceiros que atuavam a partir de demandas relacionadas a contendas políticas locais nordestinas. Esse registro está em todos os elementos que compõem o personagem: em sua fala, no modo de se comportar, na composição do figurino e do ambiente em que os personagens se inserem.

In the Clowns' street production, the political intrigues of the Yorkists and the Lancastrians gain regional contours. Visual scenic elements, such as costumes and props, reinforced the intercultural dialogue. The costumes combined skills and brocades, inspired in the garments of the English nobility, with flowers, ribbons, leather, metal and rattan, elements that compose the outfits of the cangaceiros. Only Tyrrel - renamed Tyrrel Jararaca - was dressed as a typical cangaceiro, except for his "mirrored aviator glasses, a trait immediately recognizable by a Latin American 


\title{
$244_{\text {caracaio } 8}^{\text {car }}$
}

audience as distinctive of the repressors of their former dictatorships" (D'AURIA, apud CAMATI; LEÃO, 2016, p. 99) ${ }^{8}$

Apesar de a construção visualizada até aqui já ser significativamente produtiva, um dos aspectos que mais ganha destaque na encenação do texto shakespeariano aqui em análise é a musicalidade em cena. Desde a ressignificação pelo nome da peça, as músicas já estão presentes com a indicação das "incelenças", cantos fúnebres comuns a algumas tragédias e, também, muito comuns na cultura popular nordestina. Essa construção, que aproxima as culturas presentes na apropriação, indica, além desse referencial, características do enredo da peça, todo envolto em mortes que evocam a necessidade do canto das incelenças. Além disso, remete ao pronome de tratamento "excelência", utilizado quando da referência a autoridades como Ricardo. A construção textual ganha peso quando utiliza a linguagem musical como forma de atualização, já que se torna extremamente significativa na recepção. Exemplo desse ganho pode ser identificado na fala de Elizabeth, quando responde a Ricardo os desaforos que precisa ouvir enquanto se preocupa com o rei Eduardo:

\author{
ELIZABETH \\ Lorde Ricardo, eu já sofro há muito tempo \\ Teus desaforos e alusões irônicas. \\ Por Deus, vou informar Sua Majestade \\ De tantas grosserias que suporto. \\ Preferiria ser uma criada \\ A ser rainha nessas condições! \\ Ricardo, toca aquela que eu gosto. \\ (Canta) \\ Eu vou cantando \\ Com aliança no dedo \\ Eu aqui só tenho medo \\ De Mestre Zé Mariano \\ Margaridinha botou rosas na janela \\ Pensando em vestido branco \\ Véu e flores na capela \\ TODOS \\ Ó mana, deixa eu ir
}

\begin{abstract}
8 Em tradução livre: "Na produção de rua dos Clowns, as intrigas políticas dos York e dos Lancaster ganham contornos regionais. Elementos cênicos visuais, como fantasias e adereços, reforçam o diálogo intercultural. As fantasias combinaram atributos e brocados ao serem inspiradas no vestuário da nobreza inglesa, e se mesclarem com flores, fitas, couro, metal e vime, elementos que compõem a vestimenta dos cangaceiros. Somente Tyrrel - renomeado Tyrrel Jararaca - foi vestido como um típico cangaceiro, a não ser por seus 'óculos de aviador espelhados', um traço imediatamente reconhecido por um público latino-americano como elemento distintivo dos repressores de suas ditaduras passadas" (CAMATI; LEÃO, 2016, p. 99).
\end{abstract}




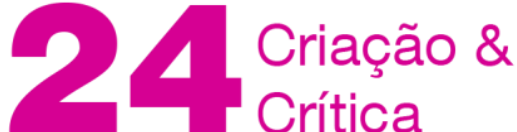

Ó mana, eu vou só

Ó mana, deixa eu ir pro sertão de Caicó (2x)

(YAMAMOTO, 2010, p. 5)

As indicações sobre a identidade de Mestre Zé Mariano, sobre o que vem a ser o sertão de Caicó e todas as implicações decorrentes das significações assumidas por essas expressões locais, ressignificam o texto estrangeiro em seu contexto novo de produção e recepção. São imagens tipicamente brasileiras, para não dizer significativamente nordestinas, ainda compreendidas no Brasil de hoje. Essas imagens fazem parte de mais uma das estratégias elencadas pelo grupo, pois, uma vez incluídas através das canções, dimensionam o texto da tragédia shakespeariana utilizada como fonte.

A canção do grupo Queen pode ser tomada como exemplo do procedimento linguístico de construção adotado pelo grupo. Após os cortes empreendidos em diversas partes do texto para completar os sentidos necessários para consecução narrativa da fábula, a canção Bohemian Rapsody tem lugar em cena com a Duquesa de York, mãe de Ricardo, fazendo uma reflexão sobre as atitudes de seu filho, como se ele falasse através da canção onde sua mãe lamenta: "Mama, just killed a man/Put a gun against his head/Pulled my trigger, now he's dead/Mama, life had just begun/But now l've gone and thrown it all away [...]' (MERCURY, 1975). A canção continua, evidenciando exatamente as relações no contexto narrativo da peça, em que Ricardo mata várias pessoas, no início de seu reinado. Escolha extremamente pontual e certeira, que encobre o corte de versos do texto shakespeariano, mas que não exclui o efeito narrativo necessário, a partir de um elemento que une a cultura-fonte à cultura-alvo, ainda que em uma língua estrangeira.

Essas canções, que retomam diferentes contextos de referência, cedem lugar também a diferentes melodias tocadas pelos próprios atores com o uso de vários instrumentos, além de apresentar um repente entoado numa espécie de disputa entre Ricardo e Tyrrel quando da contratação de seus serviços.

\section{RICARDO \\ Procuro um sujeito \\ Que queira matar \\ Que saiba matar \\ Tenho muito ouro \\ Pra lhe ofertar! \\ TYRREL \\ Mato quarqué um \\ Não temo perigo}

$9 \mathrm{Em}$ tradução livre: "Mamãe, acabei de matar um homem/Coloquei uma arma em sua cabeça/Puxei o gatilho, e agora ele está morto/Mamãe, a vida acabou de começar/Mas agora eu fui e joguei tudo pro alto [...]" (MERCURY, 1975) 


\section{$244_{\text {caracaio } 8}^{\text {cara }}$}

Não temo perigo

Se for por dinheiro

Mato até amigo

RICARDO

Pois diga o seu nome

E vá se aprontando

E vá se aprontando

Pois tem dois cabôco

Me aperriando

TYRREL

Tyrrel Jararaca

Sou vosso criado

Sou vosso criado

Me dê logo os nome

$\mathrm{E}$ fique descansado

(YAMAMOTO, 2010, p. 11-12)

Esse trecho, que continua até a resolução da contratação, ganha destaque pelo belo trabalho no linguajar feito na adaptação do texto estrangeiro pelo grupo. $O$ uso de expressões típicas da cultura-alvo, "dois cabôco", a concordância típica do falar coloquial, "os nome", referendam a peça shakespeariana nessa apropriação que teve como difícil tarefa o trabalho da linguagem, a execução de cortes de versos da peça. Esses cortes, porém, cederam lugar às canções e outras construções verbais que exemplificam muito bem o direcionamento dos usos de um texto pertencente a outra cultura em sua nova significação no contexto brasileiro. Direcionamentos esses que visam quebrar com a expectativa do público com uso de elementos componentes de uma proposta do teatro épico-dialético, além de surpreendê-los nas diferentes possibilidades de ressignificação ofertadas ao texto estrangeiro.

As canções na peça ganham ainda um novo toque ao se estudar as relações complexas das músicas do contexto potiguar com o do pop rock inglês. Algumas das canções da peça que podemos elencar são (em ordem de ocorrência): Daydrem, do grupo Wallace Collection, The Hall of Mirrors, do grupo Kaftwerk, o cantarolar do ritmo do frevo, $A$ Ciranda da Rosa Vermelha, de Alceu Valença (adaptada ao contexto da peça), $A$ Ciranda do Anel (cantiga popular), Assum Preto, de Luiz Gonzaga, Caicó, de Milton Nascimento, The Logical Song do grupo Supertramp, Cantares de Excelência (uma incelença nordestina), Sabiá, de Luiz Gonzaga, A Coroa do Rei, de Dircinha Batista, O Cabeleira, do repertório de Dona Militana, Bohemian Rapsody, da banda britânica Queen.

A mera listagem já mostra a riqueza de remissões e citações às culturas em jogo, mesmo que haja diferença enorme entre as referências musicais inglesas - rock e pop -e as brasileiras, com o frevo, a ciranda popular, o baião de Luiz Gonzaga, o samba de 


\section{Criação \&}

Dircinha Batista, a cantiga de Milton Nascimento (cujo tema é o sertão de Caicó), o romanceiro de Dona Militana, uma incelença nordestina. Vê-se que o contexto estrangeiro chega até nós por meio, necessariamente, da indústria cultural, são mercadorias bem estabelecidas no contexto do capitalismo e, até mesmo, do imperialismo cultural: são produtos arrasa-quarteirão, por assim dizer, porque embora distantes de nosso chão cultural e material, são impostos pela pressão dos mercados e se tornam referência obrigatória - incitando mesmo o desenvolvimento de um pop e rock nacionais.

Embora nomes como Luiz Gonzaga, Milton Nascimento e Alceu Valença estejam longe de ser refratários ao mercado fonográfico, Dircinha Batista e Dona Militana não são tão conhecidas, e alguns gêneros aparecem apenas como frevo, ou incelença. Os gêneros são populares, nordestinos (alguns nacionais, como o samba), deitam raízes na cultura local e, de alguma forma, lutam contra o apagamento e esquecimento. Romanceiros são épicos com estrutura literária complexa, fruto de sedimentações de histórias havidas e inventadas, infelizmente distantes do conhecimento da maioria. Essa luta de morte pela existência e importância do popular e local consegue produzir uma metáfora importante para a apropriação de Shakespeare, pois a recepção do dramaturgo elisabetano também sofre com o seu estatuto de clássico dos clássicos, perdendo de vista o contexto histórico em que surgiu, seu caráter cênico, para ganhar a altura metafísica e a-histórica do mito. Como se a peça dissesse: é preciso, sem negar as injunções do mundo contemporâneo, a primazia do mercado sobre todas as outras coisas, conseguir entender outras dinâmicas sociais e históricas, que nos ajudam a fugir da completa submissão ao existente.

O clássico Bohemian Rapsody, do grupo Queen, do alto de seu sucesso medido em lucros e fama, é questionado pela incelença e pelo romanceiro nordestinos, expressão de sua dor e de sua luta material pela vida. Esse embate de vida e morte, que passa pela relação entre as culturas e pela lógica de aniquilação do capital, ganha expressão alegórica por essas canções, fazendo a peça trazer discussões decisivas para o contexto atual. A principal delas, porque organiza as demais dimensões, é a discussão em torno da função social da arte, que está tanto em Shakespeare (e seu teatro do mundo, seu metateatro) e nos Clowns de Shakespeare. Não há fusão, nem harmonia, nem mesmo justaposição entre esses registros musicais, mas choque, contradição, dialética histórica.

\section{Considerações Finais}

As possibilidades de uso da literatura estrangeira no Brasil ganham diversas tonalidades de acordo com os contextos de recepção com que conta cada uma das produções que caminham por essa trilha. As representações de Shakespeare por grupos de teatro brasileiro com viés popular são uma dessas possibilidades. Essa prática artística que se inspira na Inglaterra dos séculos XVI-XVII, é extremamente profícua ao empreender uma tradução cultural, compreendendo as minúcias culturais na produção a 


\section{$244_{\text {caracaio } 8}^{\text {car }}$}

partir da cultura-fonte para a cultura-alvo, encaixando-se numa tradição de teatro brasileiro de rua muito forte.

Além dessa tradução entre culturas, observamos uma tradução textual, evidentemente, além da tradução cênica, com o texto se tornando imagem, música, encenação que pressupõe recepção. São apropriações bem produzidas, que bebem de todo o direcionamento do teatro popular brasileiro e da cultura-fonte, ressignificando um clássico que poderia ter seu sentido e valor anulados ao concordar com determinadas interpretações mais conservadoras e recorrentes.

Esse direcionamento indica uma das tendências das traduções e encenações de Shakespeare no Brasil, já que se mostra rica em todos os aspectos - crítica a partir do cômico, pelo figurino, pelo cenário, pelo trabalho com o texto, pela abrangência de seu alcance e pelo cuidado para com o texto estrangeiro elencado. Um Romeu e Julieta feito por palhaços, um Ricardo III perspectivado por seus traços cômicos, personagens que tocam seus próprios instrumentos, trocam os figurinos em frente do público, alguns utilizando pernas de pau, guarda-chuvas e outros elementos de cunho popular brasileiros, em encenações que tomam a rua como palco e abraçam todas as intempéries que essas escolhas podem acarretar, demonstram como o caminho para as literaturas estrangeiras no Brasil em sua tradução nos palcos é extremamente valioso e profícuo.

\section{Referências}

ANDRADE, O. Manifesto Antropófago. In: ROCHA, J. C. C.; RUFFINELLI, J. (Org.) Antropofagia hoje?: Oswald de Andrade em cena. São Paulo: É Realizações, 2011, p. 27-31. BANDEIRA, M. Os melhores poemas de Manuel Bandeira. 4. ed. São Paulo: Global, 1986. BRECHT, B. Estudos sobre teatro. Tradução Fiama Pais Brandão. Rio de Janeiro: Nova Fronteira, 1978.

CAMATI, A. S.; LEÃO, L. C. Spatial negotiations in the Brazilian street production Sua Incelença, Ricardo III by Clowns de Shakespeare. The Shakespearean International Yearbook. 16: Special Section, Shakespeare on Site. London: Routledge, 2016, p. 87-107.

"Um Shakespeare brasileiro: a música de cena em Sua Incelença, Ricardo III". Revista Cerrados. Brasília, 2013, v. 22, n. 35, p. 217-230, 2013.

CARVALHO, S. Atitude modernista no teatro brasileiro. In: ARAÚJO, A.; AZEVEDO, J.; TENDLAU, M. (orgs). Próximo ato: teatro de grupo. São Paulo: Itaú Cultural, 2011, p.100-105.

"Clowns de Shakespeare misturam guerra inglesa e sertão nordestino em Sua Incelença, Ricardo IIl". Disponível em: <http://www.miguelarcanjoprado.com/2012/07/21/clowns-deshakespeare-misturam-guerra-inglesa-e-sertao-nordestino-em-sua-incelenca-ricardo-iii/>.

Acesso em: 27 abr. 2019

CLOWNS DE SHAKESPEARE - SÓ MAIS UM SITE WORDPRESS. Disponível em: $<$ https://www.clowns.com.br/>. Acesso em: 23 abr. 2019

COSTA, Iná C. "O teatro de grupo e alguns antepassados". In: ARAÚJO, A.; AZEVEDO, J.; TENDLAU, M. (orgs). Próximo ato: teatro de grupo. São Paulo: Itaú Cultural, 2011, p. 51-5. 
D'AURIA, V. "Shakespeare's Clowns: an irreverent and magical Brazilian version of Richard III'. Multicultural Shakespeare: Translation, Appropriation and Performance, 2013, v. 10, n. 25, p. 137. FARIA, J. R. História do teatro brasileiro. Volume 1: das origens ao teatro profissional da primeira metade do século XX. São Paulo: Perspectiva, Edições SESCSP, 2012.

História do teatro brasileiro. Volume 2: do modernismo às tendências contemporâneas. São Paulo: Perspectiva: Edições SESCSP, 2013.

FARIA, J. R. Ideias teatrais: o século XIX no Brasil. São Paulo: FAPESP: Perspectiva, 2011.

FERNANDES, Sílvia. Verbete Grupos teatrais. GUINSBURG, J.; FARIA, J. R.; LIMA, M. A. (coordenação). Dicionário do teatro brasileiro: temas, formas e conceitos. $2^{\mathrm{a}}$ ed. rev. e ampl. São Paulo: Perspectiva. Edições Sesc, 2009, p. 162-4.

GRUPO DE TEATRO CLOWNS DE SHAKESPEARE - PRIMEIRO SINAL. Disponível em: $<$ http://www.primeirosinal.com.br/grupo-de-teatro-clowns-de-shakespeare>. Acesso em: 08 jan. 2018. GOMES, C. M. William Shakespeare no Brasil. Anais da Biblioteca Nacional. Vol. 79. 1959.

GOMES, E. Shakespeare no Brasil. Departamento de Imprensa Nacional. São Paulo: MEC, 1961.

GUERIOS, A. M. A Atualidade de Shakespeare: Um estudo sobre Romeu \& Julieta do Grupo Galpão. 2017. 140 f. Dissertação de Mestrado. Universidade Estadual de Maringá (UEM). Maringá, 2017.

MARTINS, M. A tradução do drama shakespeariano por poetas brasileiros. Revista IPOTESI. Juiz de Fora, vol. 13, n.1, p. 27-40, jan-jul 2009. Disponível em: <http://www.ufj..br/revistaipotesi/files/2011/04/5-A-tradu\%C3\%A7\%C3\%A3o-do-d.ramashakespeariano.pdf>. Acesso em: 10 fev. 2019.

MELLO, K. B. Boal em três tempos no Arena: texto, cena, crítica e teoria. Dissertação defendida na UEM, Maringá. 2016. 193 páginas. Disponível em: <http://www.ple.uem.br/defesas/pdf/kbmello.pdf>. Acesso em: 20 jan. 2019.

MERCURY, F. Bohemian Rapsody. A Night at the Opera. Lado B. EMI: 1975. Disponível em: <https://www.youtube.com/watch?v=fJ9rUzIMcZQ>. Acesso em: 05 mai. 2019.

MIT Global Shakespeares - Video and performance archive. Disponível em: <https://globalshakespeares.mit.edu/>. Acesso em: 27 abr. 2019.

PAVIS, P. O teatro no cruzamento de culturas. Tradução de Nanci Fernandes. São Paulo: Perspectiva, 2015.

SHAKESPEARE, W. Teatro completo. Tradução de Barbara Heliodora. São Paulo: Editora Nova Aguilar, 2016. Vol. 3.

WORTHEN, W. B. Shakespeare and the force of modern performance. Cambridge: Cambridge University Press, 2003.

\section{Recebido em: 15/05/2019 Aceito em: 26/05/2019}

Referência eletrônica: TOMIELLO, Angélica; FLORY, Alexandre Villibor. Um Shakespeare popular no Brasil do século XXI - Anotações em torno da apropriação de Ricardo III pelo grupo Clowns de Shakespeare. Criação \& Crítica, n. 24, p., out. 2019. Disponível em: <http://revistas.usp.br/criacaoecritica>. Acesso em: dd mmm. aaaa. 